\title{
Racial Disparities Associated with the Prevalence of Vaccine and Non-Vaccine HPV Types and Multiple HPV Infections between Asia and Africa: A Systematic Review and Meta-Analysis
}

\author{
Jude Ogechukwu Okoye ${ }^{1 *}$, Chiemeka Franklin Chukwukelu², Simon Imakwu \\ Okekpa $^{3,4}$, Samuel Ifedioranma Ogenyi ${ }^{1}$, Ifeoma Nora Onyekachi-Umah ${ }^{5}$, \\ Anthony Ajuluchukwu Ngokere ${ }^{1}$
}

\begin{abstract}
Background/Objective: Cervical Cancer is the 6th most common and 3rd most deadly cancer among women. Despite the fact that the majority of the countries in Asia and Africa have a similar economy and low life expectancy, the mean age-standardized incidence rate (ASIR) of cervical cancer is substantially higher in Africa than in Asia. This study identified the correlates of the higher ASIR rates in Africa relative to Asia against two timelines; 2004-2009 and 2010-2017. Methods: Peer-reviewed articles published between 2004 and 2017 were selected using the PRISMA standard. Sources of articles included Google Scholar, Scopus, PubMed Central, and EMBASE. Search keywords included: HPV genotypes, cervical cancer, HPV vaccine, and multiple infections in Africa and Asia. Result: Twenty-nine and seventeen full-length articles were selected from Africa and Asia, respectively. The pooled prevalence of HPV infection up to 2017 was higher in Africa (41.8\%; 95\% CI: 35.9, 47.7) than in Asia (24.2\%; 95\% CI: 16.22, 32.2) at $\mathrm{p}<0.001$. Between 2004-2009 and 2010-2017 timelines, the pooled prevalence of HPV infection decreased from $49.1 \%$ to $36.7 \%$ (OR': $1.66,95 \%$ CI: $1.51-1.80$ ) in Africa and increased from $16.9 \%$ to $20.5 \%$ (OR': $0.79,95 \%$ CI: 0.71-0.86) in Asia. However, the pooled prevalence of multiple HPV infections and non-vaccine high-risk HPV infections were higher among African women diagnosed with cancer (30.9\% and 5.2\%) than their Asian counterparts $(21.0 \%$ and $2.0 \%$, respectively) at $\mathrm{p}<0.001$. Additionally, the pooled prevalence of the five most prevalent high-risk HPV types in Africa were HPV16 (35.3\%), HPV52 (14.2\%), HPV35 (12.4\%), HPV18 (10.4\%), and HPV58 (10.0\%), while that of Asia were HPV16 (37.3\%), HPV52 (16.2\%), HPV58 (14.7\%), HPV33 (7.4\%) and HPV18 (7.2\%). Conclusion: This study suggests that the higher prevalence of HPV, multiple HPV and non-vaccine HPV infections could be responsible for the higher ASIR in Africa than in Asia.
\end{abstract}

Keywords: Cervical Cancer- Human Papillomavirus genotypes- Vaccine- Africa and Asia

Asian Pac J Cancer Prev, 22 (9), 2729-2741

\section{Introduction}

Cervical cancer is the $9^{\text {th }}$ most common cancer in world, and the $6^{\text {th }}$ most common and 3rd most deadly cancer among women (Fitzmaurice et al., 2019). Studies show a minor reduction in age standardized incidence rate (ASIR per 100,000) from 14.5 to 13.1 between 2017 and 2018, and a minor increase in the age standardized mortality rate (ASMR per 100,000) from 6.1 to 6.9 within the same period (Fitzmaurice et al., 2019; Arbyn et al., 2020). Despite the fact that majority of the countries in Asia and Africa have similar economy (less developed), low life expectancy and high mortality-to-incidence rate (Chen et al., 2017), the mean ASIR/ASMR of cervical cancer was higher in Africa (29.4/19.8) than in Asia (11.3/6.2) as of 2018 (Arbyn et al., 2020). The findings of Canfell et al., (2017) suggest that the high mortality rate among cervical cancer patients in Africa is associated with low access rate to treatment. However the reason for the high incidence rate of the disease in Africa remains unknown. As of 2018, the ASIR/ASMR varies: 43.1/20.0, 40.1/30.0, 29.6/23.0/, 26.8/21.1, and 7.2/5.1 in Southern, Eastern, Western, central, and Northern Africa, respectively (Arbyn et al., 2020). This shows that

${ }^{1}$ Department of Medical Laboratory Science, Faculty of Health Sciences and Technology, Nnamdi Azikiwe University, Nnewi Campus, Anambra State, Nigeria. ${ }^{2}$ Medbury Medical Services, Warri, Nigeria. ${ }^{3}$ Oncological and Radiological Sciences Cluster, Advanced Medical and Dental Institute, Universiti Sains Malaysia, Pulau Pinang Malaysia. ${ }^{4}$ Department of Medical Laboratory Science, Faculty of Health Sciences, Ebonyi State University, Abakaliki, Ebonyi State, Nigeria. ${ }^{5}$ Deworm the World Initiative, Evidence Action, Abuja, Nigeria.*For Correspondence: jog.okoye@unizik.edu.ng 
Northern Africa had the least ASIR/ASMR in Africa, yet these values are higher than that of Western Asia, the least affected Asian sub-region (4.1/2.5) (Arbyn et al., 2020). Of note also, the ratio of cervical cancer attributable to HPV in Sub-Saharan Africa and Northern Africa/Western Asia is 9.3:1 (de Martel et al., 2017). Abryn et al. and Martel et al. attributed the low ASIR in Northern Africa and Western Asia to low prevalence of HPV. They did not offer any reasons for the variation in ASIR of cervical cancer and prevalence. We however hypothesize that this could be related to the peculiar HPV subtypes found in Africa and the type of vaccines adopted in the African sub-regions.

Commonly used HPV vaccines include bivalent (HPV16/18), quadrivalent (HPV6/11/16/18) and nonavalent vaccines (Gardasil 9; 6/11/16/18/31/33/45/52/58) (Center for Disease Control and Prevention, 2019). The first two vaccines are widely used in Africa but the nonavalent vaccine which has a global estimated efficacy of $87-89.5 \%$ in prevention of cervical cancer worldwide, is yet to be widely adopted in Africa (de Martel et al., 2017; Muñoz et al., 2003). Barriers to implementation of national vaccination programs in African countries include inadequate infrastructure and finances, limited health worker training, vaccine cost, and cold chain capacity constraints (Black et al., 2018). Even if nonavalent vaccine is widely distributed in Africa, majority of the countries in sub-Saharan Africa would not reach HPV elimination by vaccination alone. This is because, if HPV vaccination were to eradicate HPV types $6,11,16,18$, $31,33,45,52$, and 58 , the incidence of cervical cancer will still be $>4 / 100,000$ due to other non-vaccine high risk HPV (hrHPV) types that are not currently covered (Brisson et al., 2020). Furthermore, the effectiveness of this vaccine will depend on the rate of HIV infection in the target population which in turn drives multiple HPV infection. In Asia, the prevalence of multiple HPV infection in normal and abnormal cervix is $5.1-25.2 \%$ and 10.6-33.3\%, respectively (Muderris et al., 2019; Ge et al., 2019; Al-Lawati et al., 2020) whereas in Africa, this is $3.9 \%-15.8 \%$ and $22.9-35.7 \%$, respectively (Keita et al., 2009; Piras et al., 2011; Ndizeye et al., 2019). This underscores the fact that multiple HPV infection limits the efficacy of available vaccine to prevent the development of cervical cancer. This review aimed at identifying the prevalent HPV types in Asia and Africa both in the general population and among women with cervical abnormalities. It also assesses the paradigm shift in the prevalence of HPV infection in Africa and Asia between two timelines; 2004-2009 and 2010-2017. It determined the prevalence of HPV infection preventable by available vaccines.

\section{Materials and Methods}

Peer-reviewed articles published in Africa $(\mathrm{n}=29)$ and Asia $(n=17)$ between 2004 and 2017 were selected and screened using the PRISMA standard (Figure1) (Liberati et al., 2009; Moher et al., 2009).

\section{Literature searches and Data sources}

Sources of articles include Google Scholar, Scopus,
PubMed Central, and EMBASE. Search keywords included "prevalence or frequency of HPV types among women Asia AND Africa", "distribution of HPV types among women with and without cervical cancer in Africa and Asia", "vaccine AND non-vaccine HPV types in Africa AND Asia", cervical cancer attributed to HPV infection in Africa and Asia", and cervical cancer related mortality in Africa and Asia. Titles of cohort and case-controlled studies published between 2000 and 2019 were searched for using keywords and mesh terms: ('HPV' and 'human papillomavirus') AND ('ICC' and 'Invasive cervical cancer') AND ('prevalence' OR 'incidence' OR 'distribution' OR 'genotype'), AND ('Africa'), AND ('Asia'). We also searched for unpublished studies (grey literature) by evaluating ClinicalTrials.gov (NIH), and International Clinical Trial Registry Platform (WHO). Inclusion criteria included: Studies with frequency of HPV infection, must be full-length articles and involve cervical cancer, and the articles must involve Africa and Asia. Exclusion criteria: Articles not written in English, abstracts, non-full-length article, and articles without specific frequency of HPV types, articles not involving Africa and Asia as well as articles not involving cervical cancer.

\section{Data collection and extraction}

The vital information extracted for analysis included: participant characteristics such as sample size, cases of among African and Asian women, prevalence of any HPV infection and multiple HPV infection, HPV types $(16,18,31,33,35,39,45,51,52,53,56,58,59,66$, $68,82,6$ and 11), mean age, recruitment method, period of data collection, and study location and region (according to WHO classification). We investigated the frequency of HPV infection in between the two continents. When calculating the prevalence of any HPV infection (women who tested positive for any HPV type), an individual may have acquired both HPV 35 and HPV45 or more but it would only count as one event. The range of high-risk HPVs investigated in the selected studies varied, thus when calculating the prevalence of an HPV type, only studies or cases that investigated that particular HPV type were considered. To assess the impact of timelines on the prevalence of HPV infection, data points were categorized into pre-and up to 2009, and from 2010 and up to 2017.

\section{Data analyses}

Pooled prevalence of HPV prevalence were presented in forest plots. Chi-square $\left(X^{2}\right)$ and Odds ratio analyses were used in calculating the difference in HPV types between Africa and Asia against different timelines (in GraphPad Prism, version 6.0). Significance was set at $\mathrm{p}<0.05$

\section{Results}

Based on the inclusion criteria and according to World Health Organization classification of geographic regions, West Africa had the highest number of participants (7,313; $\mathrm{n}=14$ studies $)$, followed by East Africa $(7,240 ; n=8$ studies), Central Africa (2,167; $\mathrm{n}=2$ studies), North Africa 
( $855, n=3$ studies), South Africa ( $153 ; n=1$ study). One mixed study involving Tanzania and South Africa (with 194 participants) was also included. Figures $1 \mathrm{~b}$ and $1 \mathrm{c}$ show the pooled prevalence of any HPV infection in Africa and Asia, respectively. Studies in Africa revealed that HPV16, HPV18 and HPV52 ranked first/second in $44.8 \% / 17.2 \%(13 / 29 ; 5 / 29), 10.3 \% / 10.3 \%(3 / 29)$ and $13.8 \% / 10.3 \%(4 / 29 ; 3 / 29)$, respectively whereas studies in Asia revealed that they ranked first/second in $70.6 \% / 23.5 \%(12 / 17 ; 4 / 17), 0.0 \% / 11.8 \%(0 / 17 ; 2 / 17)$, and $23.5 \% / 17.6 \%(4 / 17 ; 3 / 17)$, respectively. Interestingly, HPV35 ranked first and second in 17\% (5/29) and 20.7\% (6/29) in studies in Africa but it only ranked fifth in one study from Asia (5.9\%; 1/17, Tables 1a and 1b). Higher prevalence of HPV and multiple infections were observed in Africa than in Asia, both in the general population and among women with cervical abnormalities $(\mathrm{p}<0.001$; Tables 2-4; see supplementary and supporting data). Between 2004-2009 and 2010-2017 timelines, the pooled prevalence of HPV infection decreased from $49.1 \%$ to 36.7\% (OR': 1.66, 95\% CI: 1.51-1.80) in Africa and increased from $16.9 \%$ to $20.5 \%$ (OR': 0.79 , 95\% CI: 0.71-0.86).

\section{Prevalence of HPV types in multiple infection}

Considering the general population, significant differences in the prevalence of HPV types were observed between Africa and Asia, except for HPV6 $(\mathrm{p}<0.001)$. High differences were observed between the two continents with regards to HPV16, HPV35, HPV18, HPV31 and HPV53/66 prevalence, in descending order of rank (Table 2). There were no observed differences between African and Asian studies with respect to vaccine hrHPV ( $p>0.05)$ whereas, significant differences were observed between African and Asian studies with respect to non-vaccine hrHPV $(\mathrm{p}<0.001)$. lrHPV showed no differences between African and Asian studies ( $p>0.05$; Figure 2a). The first five HPV types with the highest

Table 1a. Specific Distribution of Studies, Timeline, Sample Size and Prevalence of Multiple HPV Infections in Africa

\begin{tabular}{|c|c|c|c|c|c|c|}
\hline \multirow[t]{2}{*}{ Autho r(s) } & \multirow[t]{2}{*}{ Location/Country } & \multirow[t]{2}{*}{$\begin{array}{c}\text { Duration of } \\
\text { Study }\end{array}$} & \multirow{2}{*}{$\begin{array}{c}\text { Age } \\
\text { range/Mean } \\
\text { years }\end{array}$} & \multirow{2}{*}{$\begin{array}{c}\text { Cases } \\
\mathrm{N}\end{array}$} & \multirow{2}{*}{$\begin{array}{c}\text { Multiple } \\
\text { HPV }\end{array}$} & \multirow{2}{*}{$\begin{array}{c}\text { Order of } \\
\text { Prevalence } \\
\text { High-risk HPV }\end{array}$} \\
\hline & & & & & & \\
\hline Obiri-Yeboah et al 2017 & Ghana & 2017 & $\leq 29-60+/ 44$ & 329 & $113(34.3)$ & $35,58,52,18,56$ \\
\hline Yakub et al 2019a & Northern Nigeria & $2016-2017$ & $20-50 / \mathrm{NA}$ & 220 & $25(11.4)$ & $35,16,45,33,18$ \\
\hline Mutombo et al 2019 & D.R. Congo & $2015-2017$ & $25-60+/ 46$ & 1846 & $54(2.9)$ & $56,52,53,35.45$ \\
\hline Ghedira et al 2016 & Tunisia & 2016 & $17-73 / \mathrm{NA}$ & 471 & $5(1.1)$ & $16,31,58,66,56$ \\
\hline Ndizeye et al 2019 & Burundi & $2013 / 2016$ & $17-65 / 38$ & 600 & $64(10.7)$ & $16,18,33,58,31$ \\
\hline Nchome et al 2020 & Tanzania & $2015-2016$ & $25-60 / \mathrm{NA}$ & 3416 & NA & $52,16,58,18,35$ \\
\hline Vassilakos et al 2016 & Madagascar & 2015 & $30-65 / \mathrm{NA}$ & 403 & $143(35.4)$ & $53,68,52,35,16 / 33$ \\
\hline Marembo et al 2019 & Zimbabwe & 2015 & $18-83 / 39$ & 136 & $26(19.1)$ & $18,52,16,58,51$ \\
\hline Belglaiaa et al 2015 & Morocco & 2014-2015 & $18-76 / \mathrm{NA}$ & 232 & $34(14.7)$ & $16,53,18,52,31 / 33 / 56$ \\
\hline Nyasenu et al 2019 & Togo & $2014-2015$ & $20-50+/ \mathrm{NA}$ & 324 & $7(2.2)$ & $18,45,16,68,35 / 52 / 53$ \\
\hline Menon et al 2016 & Kenya & $2009-2015$ & $18-61 / 28$ & 616 & $202(32.8)$ & $16,53,52,56,58$ \\
\hline Krings et al 2019 & Ghana & 2014 & $18-65 / 31$ & 1943 & $188(9.7)$ & $16,52,35,59,66$ \\
\hline Ezechi et al 2014 & Southern Nigeria & 2014 & $18-81 / \mathrm{NA}$ & 515 & $28(5.4)$ & $16,35,58,31,18 / 52$ \\
\hline Youssef et al 2016 & Egypt & $2013-2014$ & $20-40 / 29$ & 152 & $39(25.7)$ & $16,18,31,58 / 59,45$ \\
\hline Awua et al 2020 & Ghana & $2012-2013$ & $15-65 / \mathrm{NA}$ & 226 & $151(66.8)$ & $16,35,58,45,18$ \\
\hline Boumba et al 2015 & Congo & 2012 & $16-72 / 43$ & 321 & $21(6.5)$ & $16,33,18,31,35$ \\
\hline Akarolo-Anthony et al 2013 & Northern Nigeria & 2012 & $18-45+/ 37$ & 278 & $23(8.3)$ & $35,56,58,45 / 59,68$ \\
\hline Reddy et al $2015 \mathrm{a}$ & Malawi & 2011-2012 & $25-59 / \mathrm{NA}$ & 294 & NA & $58,35,16,33 / 52,18$ \\
\hline Namujju et al 2011 & Uganda & 2011 & $\mathrm{NA} / 23$ & 1943 & $366(18.8)$ & $18,16,45,33,52$ \\
\hline Sweet et al 2020b & Kenya & $2009-2011$ & $18-50 / \mathrm{NA}$ & 348 & $14(4.0)$ & $52,31,16 / 51,35 / 45$ \\
\hline Dols et al 2012 & Tanzania/S. Africa & $2008-2010$ & $20-73 / \mathrm{NA}$ & 194 & NA & $52,16,66,33 / 51,35$ \\
\hline Piras et al 2011 & Benin & 2009 & $15-70 / \mathrm{NA}$ & 427 & $57(13.3)$ & $59,35,16,18,58$ \\
\hline Said et al 2009 & S. Africa & 2009 & NA/NA & 153 & $40(26.1)$ & $35,18,58,16,66$ \\
\hline Wolday et al 2018 & Ethiopia & 2008-2009 & $18-55+/ 41$ & 233 & $3(1.3)$ & $16,35 / 45,31,56$ \\
\hline Maranga et al 2013 & Kenya & 2008-2009 & $27-68 / 35$ & 224 & $37(16.5)$ & $56,53,52,59,58$ \\
\hline Vidal et al 2011 & Tanzania & $2008-2009$ & $\mathrm{NA} / 40$ & 215 & $149(69.3)$ & $16,35,58,45,51$ \\
\hline Guthrie et al 2020a & Kenya & $2007-2009$ & $18-50 / \mathrm{NA}$ & 283 & $122(43.1)$ & $52,16 / 18,51,35$ \\
\hline Keita et al 2009 & Guinea & $2006-2008$ & $15-64 / \mathrm{NA}$ & 831 & $386(46.5)$ & $16,45,52,33,35 / 58$ \\
\hline Okolo et al 2010 & Southern Nigeria & $2004-2006$ & $15-80 / \mathrm{NA}$ & 313 & $73(23.3)$ & $16 / 35,31,56,58$ \\
\hline
\end{tabular}

Keys, AR; Age range, MA, mean age, Prev.; Prevalent, HR; high risk, NA; Not available, D.R.; Democratic Republic, S. Africa; South Africa, a; HIV infected, commercial Sex Workers 

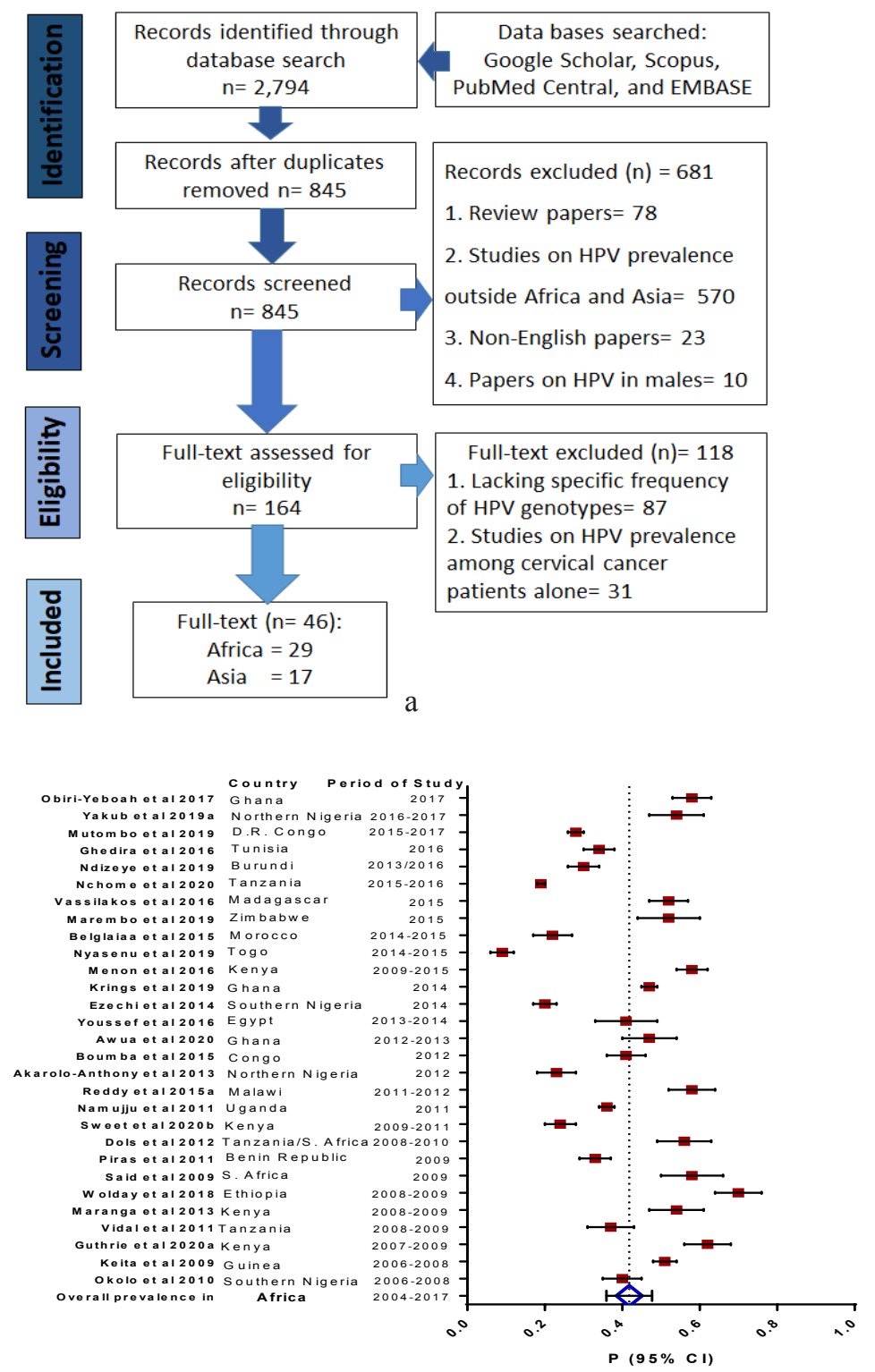

b

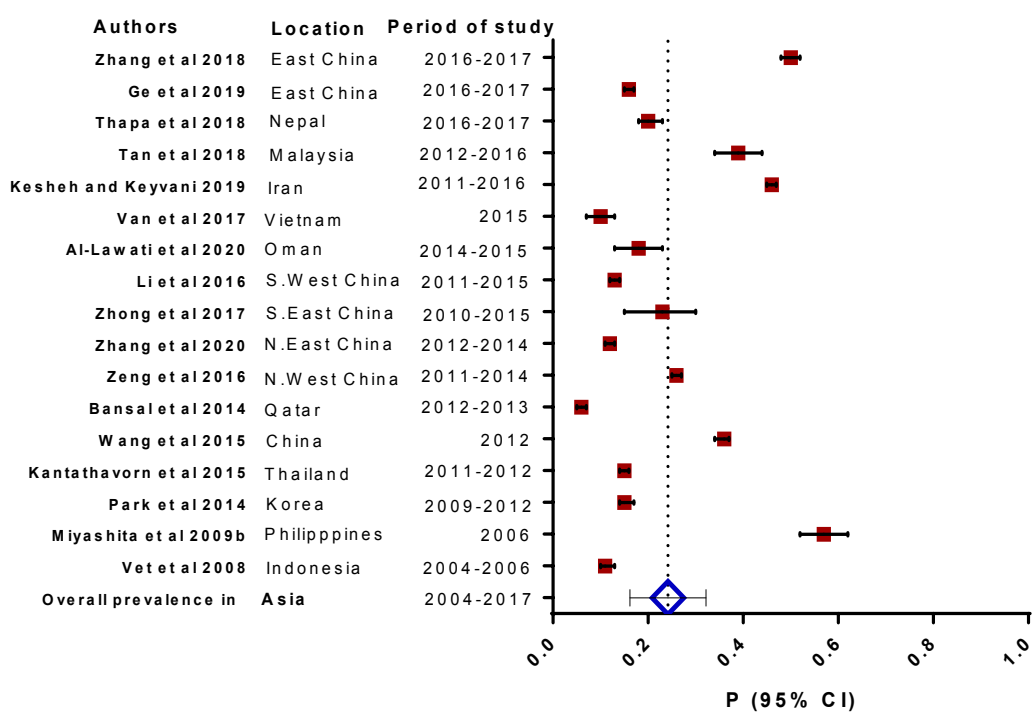

Figure 1. PRISMA Flow Chart Diagram of Study Selection. Figure 1b, Forest plot of pooled prevalence of HPV infection in Africa; Figure 1c, Forest plot of pooled prevalence of HPV infection in Asia. Figures 1b and 1c, The pooled prevalence of HPV infection up to 2017 was higher in Africa $(41.8 \%$; 95\% CI: 35.9, 47.7) than in Asia $(24.2 \%$; $95 \%$ CI: $16.2,32.2)$ at $\mathrm{p}<0.001$. 
a
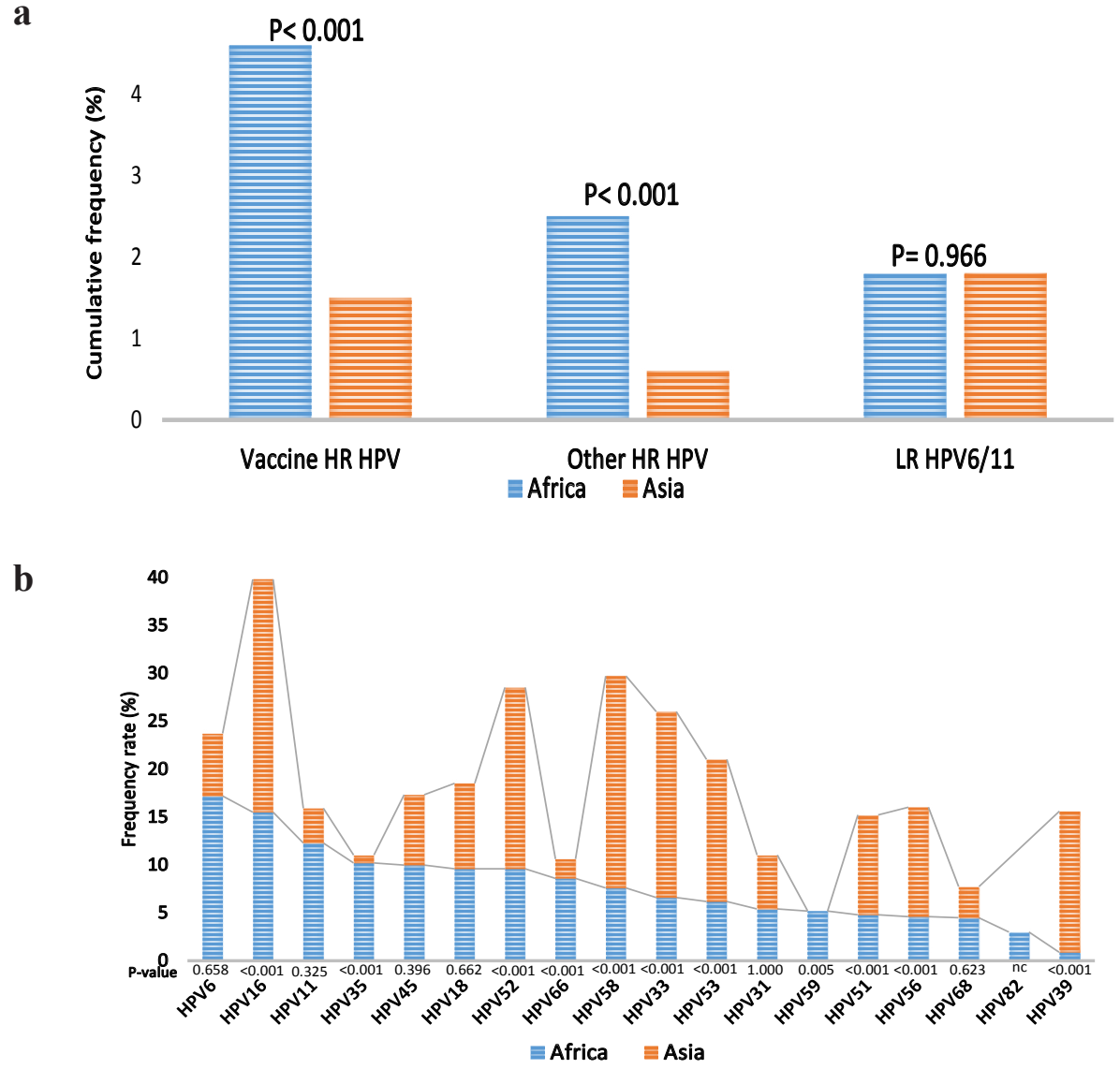

Figure 2. Frequency of HPV Genotypes in the General Population of Africa and Asia. Figure 2a, Higher prevalence of vaccine and non-vaccine HPV types were found in African than in Asia $(p<0.001)$ while similar prevalence of lrHPV types was found in Africa and Asia ( $\mathrm{p}>0.05$ ). Figure 2b, In terms of multiple infection, significant differences were observed between Africa and Asia with regards to HPV58, HPV39, HPV33, HPV35, HPV52, HPV16, HPV53, HPV56, HPV66, HPV51, HPV59, HPV45, HPV68, HPV18 and HPV31, in descending order of rank. No comparison (nc) was carried out in respect to HPV82 due to the fact it was not investigated in the selected Asian studies used for plotting this graph.

Table 1b. Specific Distribution of Studies, Timeline, Sample Size and Prevalence of Multiple HPV Infections in Asia

\begin{tabular}{lcccccc}
\hline Author (s) & Location & Duration of Study & AR/MA & Cases & Multiple & Order of Prev. \\
& & & & N & HPV & HR HPV \\
\hline Zhang et al 2018 & East China & $2016-2017$ & $18-96 / 44$ & 2612 & $346(13.2)$ & $16,52,58.18,53$ \\
Ge et al 2019 & East China & $2016-2017$ & $16-85 / \mathrm{NA}$ & 65613 & $2242(3.4)$ & $16,58,52,53,39$ \\
Thapa et al 2018 & Nepal & $2016-2017$ & $20-65 / 32$ & 998 & $61(6.1)$ & $16,39,58,33,51$ \\
Tan et al 2018 & Malaysia & $2012-2016$ & $28-77 / 49$ & 394 & $13(3.3)$ & $16,18,58,33,31$ \\
Kesheh and Keyvani 2019 & Iran & $2011-2016$ & $13-74 / \mathrm{NA}$ & 8351 & $1620(19.4)$ & $16,53,52,51,66$ \\
Van et al 2017 & Vietnam & 2015 & $18-49 / \mathrm{NA}$ & 400 & $14(3.5)$ & $16,18,58 / 59,35 / 51 / 52 / 56$ \\
Al-Lawati et al 2020 & Oman & $2014-2015$ & $18-68 / \mathrm{NA}$ & 258 & $11(4.3)$ & $82,68,18 / 53 / 56$ \\
Li et al 2016 & SW China & $2011-2015$ & $17-84 / 36$ & 28375 & $664(2.3)$ & $52,16,58,18,56$ \\
Zhong et al 2017 & SE China & $2010-2015$ & $16-77 / 36$ & 71435 & $5354(7.5)$ & $16,52,58,33,18$ \\
Zhang et al 2020 & NE China & $2012-2014$ & $25-65 / 39$ & 34587 & $676(2.0)$ & $16,58,52,53,33$ \\
Zeng et al 2016 & NW China & $2011-2014$ & $<30-50+/ \mathrm{NA}$ & 51345 & $3382(6.6)$ & $16,58,56,39,18$ \\
Bansal et al 2014 & Qatar & $2012-2013$ & $16-84 / 41$ & 3008 & $6(0.2)$ & $16,56,59,18 / 31 / 45$ \\
Wang et al 2015 & China & 2012 & NA & 9641 & $486(5.0)$ & $16,52,58,59,56$ \\
Kantathavorn et al 2015 & Thailand & $2011-2012$ & $20-70 / 44$ & 5906 & NA & $52,16,51,53 / 58$ \\
Park et al 2014 & Korea & $2009-2012$ & $39-58 / \mathrm{NA}$ & 1998 & $40(2.0)$ & $16,18,51,58,52$ \\
Miyashita et al 2009b & Philippines & 2006 & $18-40 / 24$ & 369 & $94(25.5)$ & $52,16,66,45,59$ \\
Vet et al 2008 & Indonesia & $2004-2006$ & $15-70 / \mathrm{NA}$ & 2686 & $63(2.3)$ & $52,16,18,39,51$ \\
\hline
\end{tabular}

Keys, AR; age range, MA; mean age, HR; high risk, NW; North-Western, SW; South Western, NE; North East, NA; Not available, b; Commercial Sex Workers 
involvement in multiple infection in Africa were HPV6, HPV16, HPV11, HPV35 and HPV45 while that of Asia were HPV16, HPV58, HPV33, HPV52 and HPV53, in order of descending rank (Figure $2 b$ ).

Prevalence of HPV types among women with cervical abnormalities

The prevalent HPV types in Africa were HPV16, HPV52, HPV35, HPV18 and HPV58 while the prevalent HPV types in Asia were HPV16, HPV52, HPV58, HPV33, and HPV53, in descending order of rank. High significant differences were observed between Africa and Asia with regards to HPV35, HPV6, HPV45, HPV31, HPV58, HPV66 and HPV68, in descending order of rank (Table 3). Result showed a higher prevalence of hrHPV and $1 r H P V$ in Africa than in Asia ( $<<0.001$; Figure 3Ia). It also shows that nonavalent HPV vaccine could prevent the development of $69.3 \%$ and $83.2 \%$ of HPV attributable cervical abnormalities in Africa and Asia, respectively whereas bivalent and quadrivalent vaccines could prevent the development of about $30 \%$ and $40 \%$ of HPV associated cervical abnormalities in Africa and Asia, respectively (Figure 3Ib). Cervical abnormalities among Africa women were $68 \%, 51 \%, 14 \%$, and $67 \%$ more associated with multiple HPV infections, HPV18, HPV38 and HPV59 than the cervical abnormalities found among Asian women, respectively (Figure 3II).
Difference in HPV prevalence between 2004-2009 and 2010-2017

Overall, the prevalence of HPV infection in Africa decreased between 2004-2009 and 2010-2017 whereas it increased in Asia between the same periods. Up to 2009, the pooled prevalence of HPV and multiple HPV infections were significantly higher in Africa (49.1\% and $32.4 \%$ ) than in Asia (16.9\% and 5.1\%, respectively) at $\mathrm{p}<0.001$. Up to 2009 , there were significant differences between Africa and Asia with regards to the prevalence of HPV types in $(p \leq 0.01)$, except for HPV-82 ( $>0.05)$. Within the same period, the prevalence of vaccine and non-vaccine HPV infection were higher in Africa (5.9\% and $3.3 \%$ ) than in Asia (1.1\% and $0.7 \%$, respectively). As of 2010 and later, the pooled prevalence of HPV infection and multiple HPV infection were significantly higher in Africa (36.7\% and 14.3\%) than in Asia (20.5\% and $5.3 \%$, respectively) at $\mathrm{p}<0.001$. This reveal that the multiple HPV infection decreased by $18.1 \%$ in Africa and increased by $0.3 \%$ in Africa between the timelines of 2004-2009 to 2010-2017 (Table 4; see supplementary data). No significant difference was observed between the two continents in terms of the prevalence of HPV6 and HPV11 ( $p>0.05$ and $p<0.05$ ), respectively (Table 4$)$. As of 2010 and later, the prevalence of vaccine and non-vaccine HPV were higher in Africa (5\% and 2.5\%) than in Asia ( $1.7 \%$ and $0.7 \%$, respectively) at $\mathrm{p}<0.001$ (Figure $3 \mathrm{c}$ ). Both in Africa and Asia, the prevalence of HPV16,

Table 2. Prevalence Comparison of HPV Genotypes between African and Asian population

\begin{tabular}{|c|c|c|c|c|c|c|c|}
\hline \multirow[t]{2}{*}{ Variables } & \multicolumn{2}{|c|}{ Africa } & \multicolumn{2}{|c|}{ Asia } & \multicolumn{2}{|c|}{ Africa vs Asia } & \multirow{2}{*}{$\begin{array}{c}\text { Africa vs Asia } \\
\text { Pooled OR } \\
(95 \% \mathrm{Cl})\end{array}$} \\
\hline & $\begin{array}{c}\text { Cases } \\
(\mathrm{N})\end{array}$ & $\begin{array}{l}\text { HPV+ } \\
\text { n1 }(\%)\end{array}$ & $\begin{array}{c}\text { Cases } \\
(\mathrm{N})\end{array}$ & $\begin{array}{l}\text { HPV+ } \\
\text { n2 (\%) }\end{array}$ & n1-n2 (Rank) & $\mathrm{X} 2(\mathrm{p})$ & \\
\hline Any HPV & 17486 & $6541(37.4)$ & 287976 & $58364(20.3)$ & 17.1 & $<0.001$ & $2.35(2.27,2.41)$ \\
\hline Multiple & 13582 & $2482(18.3)$ & 282070 & $16274(5.7)$ & 12.6 & $<0.001$ & $3.65(3.46,3.82)$ \\
\hline \multicolumn{8}{|l|}{ Vaccine HR } \\
\hline HPV16 & 17486 & $1396(8.0)$ & 287976 & $9413(3.2)$ & $4.8(1)$ & $<0.001$ & $2.57(2.55,2.57)$ \\
\hline HPV18 & 17486 & $927(5.3)$ & 287976 & $2765(1.0)$ & $4.3(3)$ & $<0.001$ & $5.77(5.31,6.23)$ \\
\hline HPV31 & 17486 & $669(3.8)$ & 287976 & $1294(0.4)$ & $3.4(4)$ & $<0.001$ & $8.81(8.08,9.68)$ \\
\hline HPV33 & 17253 & $439(2.5)$ & 287976 & $1952(0.7)$ & $1.8(9)$ & $<0.001$ & $3.77(2.69,5.21)$ \\
\hline HPV45 & 17165 & $669(3.9)$ & 287976 & $534(1.9)$ & $2.0(8)$ & $<0.001$ & $21.4(19.11,23.81)$ \\
\hline HPV52 & 17165 & $857(5.0)$ & 287976 & $7686(2.7)$ & $2.3(7)$ & $<0.001$ & $1.88(1.75,2.01)$ \\
\hline HPV58 & 17486 & $641(3.7)$ & 287976 & $5878(2.0)$ & $1.7(10)$ & $<0.001$ & $1.83(1.68,1.98)$ \\
\hline \multicolumn{8}{|l|}{ Other HR } \\
\hline HPV35 & 17486 & $801(4.6)$ & 287976 & $578(0.2)$ & $4.4(2)$ & $<0.001$ & $23.87(21.33,26.58)$ \\
\hline HPV39 & 17165 & $247(1.4)$ & 287976 & $2679(0.9)$ & $0.5(16)$ & $<0.001$ & $1.53(1.35,1.75)$ \\
\hline HPV51 & 16932 & $402(2.4)$ & 287976 & $2293(0.8)$ & $1.6(12)$ & $<0.001$ & $3.03(2.72,3.39)$ \\
\hline HPV53 & 11928 & $312(2.6)$ & 276270 & $2098(0.8)$ & $2.8(5)$ & $<0.001$ & $3.51(3.13,3.97)$ \\
\hline HPV56 & 17486 & $388(2.2)$ & 287976 & $2391(0.8)$ & $1.4(14)$ & $<0.001$ & $2.71(2.44,3.03)$ \\
\hline HPV59 & 16852 & $370(2.2)$ & 287976 & $1537(0.5)$ & $1.7(10)$ & $<0.001$ & $4.18(3.74,4.66)$ \\
\hline HPV66 & 12927 & $408(3.2)$ & 278668 & $1243(0.4)$ & $2.8(5)$ & $<0.001$ & $7.27(6.49,8.08)$ \\
\hline HPV68 & 16738 & $373(2.2)$ & 284968 & $1608(0.6)$ & $1.6(12)$ & $<0.001$ & $4.02(3.60,4.48)$ \\
\hline HPV82 & 9045 & $158(1.7)$ & 101345 & $607(0.6)$ & $1.1(15)$ & $<0.001$ & $8.33(6.96,9.97)$ \\
\hline \multicolumn{8}{|l|}{ LR Type } \\
\hline HPV6 & 9265 & $186(2.0)$ & 180707 & $4188(2.3)$ & $0.3(17)$ & 0.057 & $0.86(0.74,1.00)$ \\
\hline HPV11 & 8241 & $132(1.6)$ & 180707 & $2404(1.3)$ & $0.3(17)$ & 0.034 & $1.21(1.01,1.45)$ \\
\hline
\end{tabular}


Table 3. Frequency of HPV Genotype among Women with Abnormal Cervix

\begin{tabular}{|c|c|c|c|c|c|c|}
\hline \multirow{3}{*}{$\begin{array}{l}\text { Variable } \\
\text { Abnormal } \\
\text { Cervix }\end{array}$} & \multicolumn{2}{|c|}{ Africa } & \multicolumn{2}{|c|}{ Asia } & \multicolumn{2}{|c|}{ Africa vs Asia } \\
\hline & Cases & HPV+ & Cases & HPV+ & n1-n2 (Rank) & Chi-square (p) \\
\hline & $(\mathrm{N})$ & $\mathrm{n} 1(\%)$ & $(\mathrm{N})$ & $\mathrm{n} 2(\%)$ & & \\
\hline Any HPV & 1035 & $815(78.7)$ & 961 & $820(85.3)$ & 6.6 & $<0.001$ \\
\hline Multiple & 544 & $168(30.9)$ & 757 & $159(21.0)$ & 9.9 & $<0.001$ \\
\hline \multicolumn{7}{|l|}{ Vaccine HR } \\
\hline HPV16 & 1035 & $366(35.3)$ & 961 & $358(37.3)$ & $2.0(15)$ & 0.402 \\
\hline HPV18 & 1035 & $108(10.4)$ & 961 & $69(7.2)$ & $3.2(9)$ & 0.012 \\
\hline HPV31 & 1035 & $78(7.5)$ & 961 & $25(2.6)$ & $4.9(4)$ & $<0.001$ \\
\hline HPV33 & 972 & $52(5.3)$ & 961 & $71(7.4)$ & $2.1(14)$ & 0.076 \\
\hline HPV45 & 1035 & $84(8.1)$ & 961 & $12(1.2)$ & $6.9(3)$ & $<0.001$ \\
\hline HPV52 & 960 & $136(14.2)$ & 961 & $156(16.2)$ & $2.0(15)$ & 0.227 \\
\hline HPV58 & 1035 & $104(10.0)$ & 961 & $141(14.7)$ & $4.7(5)$ & 0.002 \\
\hline \multicolumn{7}{|l|}{ Other HR } \\
\hline HPV35 & 960 & $119(12.4)$ & 961 & $15(1.6)$ & $10.8(1)$ & $<0.001$ \\
\hline HPV39 & 960 & $25(2.6)$ & 961 & $22(2.3)$ & $0.3(17)$ & 0.661 \\
\hline HPV51 & 960 & $62(6.5)$ & 961 & $28(2.9)$ & $3.6(8)$ & $<0.001$ \\
\hline HPV53 & 742 & $23(3.1)$ & 961 & $32(3.3)$ & $0.2(18)$ & 0.89 \\
\hline HPV56 & 972 & $47(4.8)$ & 961 & $16(1.7)$ & $3.1(10)$ & $<0.001$ \\
\hline HPV59 & 960 & $33(3.4)$ & 961 & $20(2.1)$ & $2.3(13)$ & 0.072 \\
\hline HPV66 & 867 & $58(6.7)$ & 961 & $23(2.3)$ & $4.4(6)$ & $<0.001$ \\
\hline HPV68 & 897 & $34(3.8)$ & 961 & $9(0.9)$ & $2.9(11)$ & $<0.001$ \\
\hline HPV82 & 769 & $27(3.5)$ & 757 & $7(0.9)$ & $2.6(12)$ & 0.001 \\
\hline \multicolumn{7}{|l|}{ LR Type } \\
\hline HPV6 & 245 & $20(8.2)$ & 757 & $9(1.2)$ & $7.0(2)$ & $<0.001$ \\
\hline HPV11 & 308 & $16(5.2)$ & 757 & $10(1.3)$ & $3.9(7)$ & 0.001 \\
\hline
\end{tabular}

HPV56, HPV51, HPV39 and HPV45 decreased from 2004 to 2017 (5\% versus $16.0 \%, 1.5 \%$ versus $0.3 \%, 1.3 \%$ versus $0.1 \%, 0.7 \%$ versus $0.1 \%$, and $0.6 \%$ versus $0.7 \%$, respectively) while the prevalence of HPV53, HPV 31 , HPV 68 and HPV33 increased $(1.1 \%$ versus $0.2 \%, 0.9 \%$ versus $0.2 \%$, and $0.3 \%$ versus $0.8 \%$, and $0.2 \%$ versus $0.6 \%$, respectively) from 2004 to 2017 . This suggests that among hrHPVs the prevalence of HPV16 decreased the most whereas HPV53 increased the most. In Africa, the prevalence of HPV35, HPV59, HPV58, and HPV52 decreased $2.4 \%, 2.0 \%, 1.8 \%$, and $0.4 \%$ from $2004-2009$ to 2010-2017 while the prevalence of HPV66 and HPV18 increased by $1.3 \%$, and $0.3 \%$, respectively. In Asia, the prevalence of HPV82 and HPV18/66 decreased from 2004-2009 to $2010-2017$ by $1.1 \%$ and $0.4 \%$, respectively. Conversely, the prevalence of HPV 58 and HPV52 increased by $1.5 \%$, and $0.4 \%$, respectively while the prevalence of HPV35 and HPV59 remained unchanged (Table 4; see supplementary data). In Africa, the risk of HPV infection and multiple HPV infections were 66\% and approximately 3 times higher in $\leq 2009$ than in $\geq 2010$, respectively whereas in Asia, the risk of HPV infection and multiple HPV infections were $11 \%$ and $3 \%$ lower in $\leq 2009$ than in $\geq 2010$, respectively (Figure 4 I).

Prevalence of HPV types in the African sub-regions The highest and lowest prevalence of HPV infection as well as highest and lowest multiple infections were found in South Africa and Central Africa respectively. South Africa had the highest prevalence of HPV18, HPV45, HPV58, HPV35, HPV39, HPV51, and HPV59 while West Africa had the highest prevalence of HPV52, HPV53, HPV56, HPV66, and HPV82. East Africa had the highest prevalence of HPV31, HPV33, and HPV11 while North Africa had the highest prevalence of HPV16 and HPV6. Central Africa had the highest prevalence of HPV68. North Africa had the lowest prevalence of HPV45, HPV52, HPV58, HPV35, HPV66, HPV68, and HPV82 (Table 5; supplementary data). The pool prevalence of HPV in North, East, Central, West and South Africa were 32.0\%, 30.6\%, 30.1\%, 44.9\% and $58.2 \%$, respectively while the prevalence of multiple HPV infections were $9.1 \%, 24.4 \%, 3.5 \%, 20.0 \%$ and $26.1 \%$, respectively (see supplementary data). Result showed that the prevalence of non-vaccine hrHPV types were lower in the North and East Africa (Figure 4IIa) while the prevalence of HPV preventable by nonavalent vaccine was higher in both regions than other African sub-regions (Figure 4IIb).

\section{Discussion}

The incidence of cervical cancer in a population majorly depends on the prevalence of HPV infection 

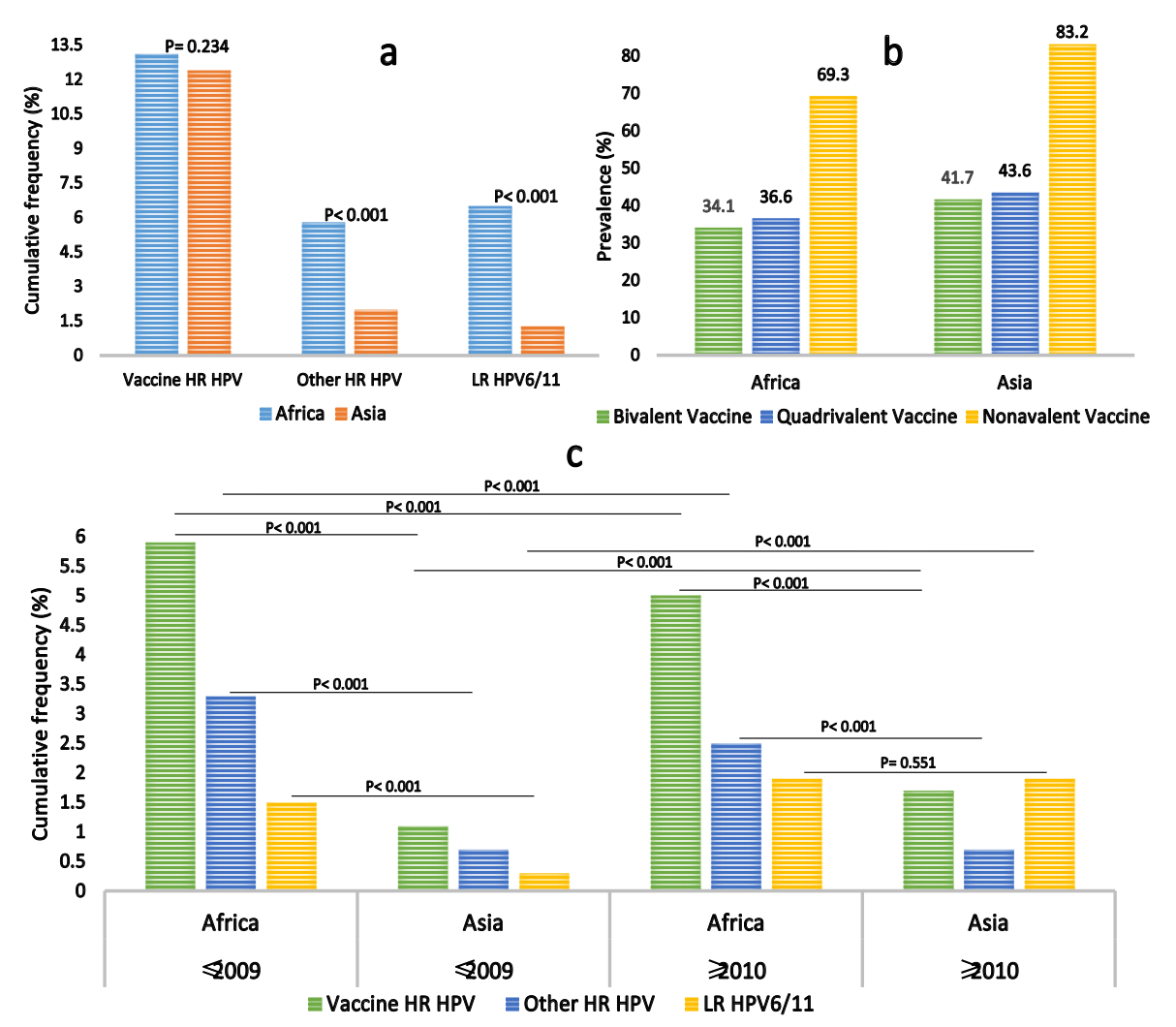

Figure 3I. a) Frequency Comparison of HPV Genotypes in African and Asian women Irrespective of Cervical Status, b) Prevalence of HPV-associated cervical abnormalities preventable by available vaccines and c) Cumulative frequency comparison of vaccine and Non-vaccine HPV between Africa and Asia with regards to timelines. Figure 3I. No significant difference was observed between Africa and Asia studies in terms of vaccine hrHPV genotypes. However, significance differences were observed between Africa and Asian studies in terms of non-vaccine other hrHPV types and lrHPV16/11 ( $p<0.001$; Figure 3Ia). Figure 3Ib shows that quadrivalent vaccine may have mild edge over bivalent vaccine in preventing the development of cervical abnormalities both in Africa and Asia while nonavalent vaccine could exert almost twice the effect of bivalent and quadrivalent vaccines in forestalling the development of cervical abnormalities. Figure 3Ic, Cumulatively, as of 2009 and 2017, the prevalence of vaccine and non-vaccine hrHPV were significantly higher in Africa than in Asia $(\mathrm{p}<0.001)$. As of 2009 , the prevalence of lrHPV was significantly higher in Africa than in Asia $(p<0.001)$ while the prevalence of the viruses were similar between both Continents in 2017 at $\mathrm{p}>0.05$.

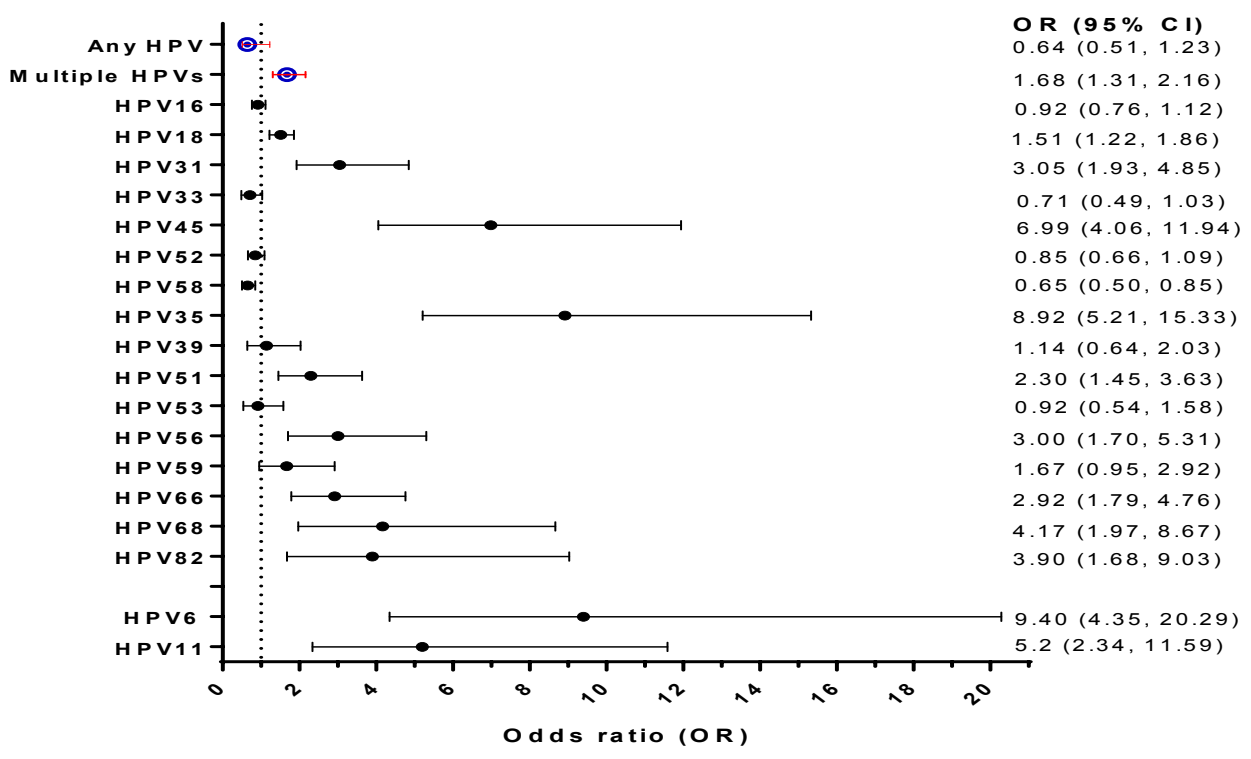

Figure 3II. Meta-analysis of the Association between HPV Genotypes and Cancer (Africa versus Asia; derived from table 3). Figure 3II. Cervical abnormalities detected among Africa women were approximately 2 times, 3 times, 4 times, 5 times, 7 times, and 9 times more associated with HPV51, HPV-31/56, HPV-68/82, HPV11, HPV45, HPV$35 / 6$ than the cervical abnormalities detected among Asian women, respectively. 

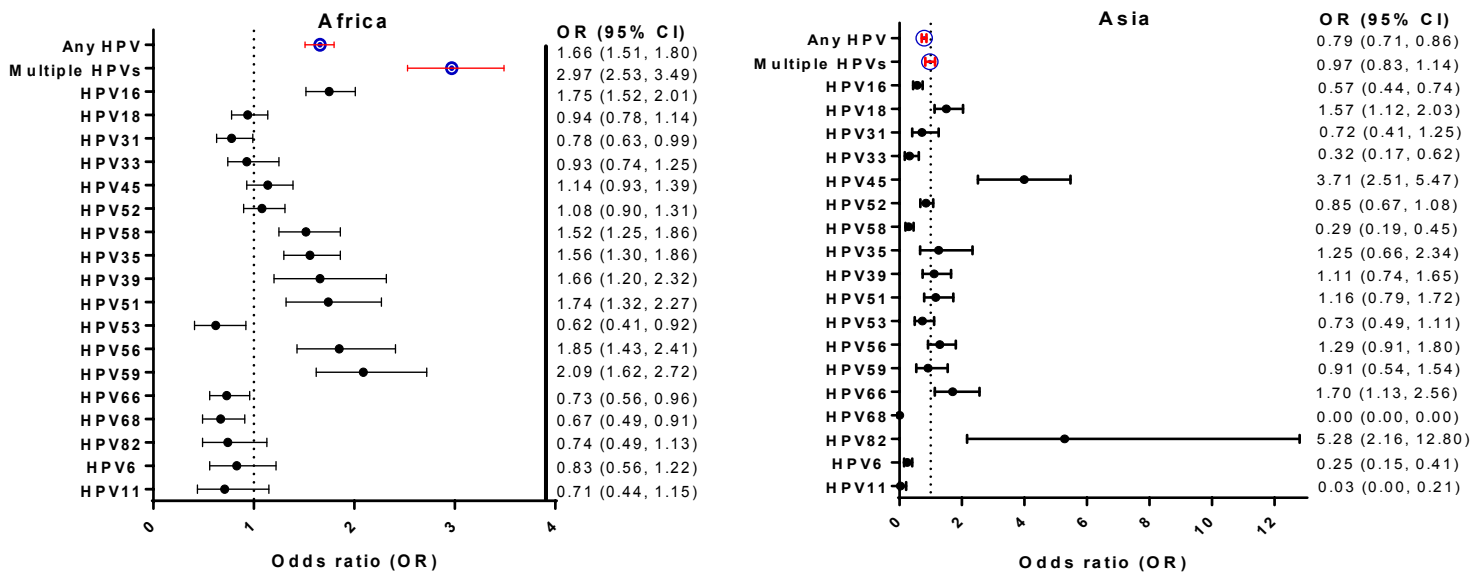

Figure 4I. Prevalence Comparison of HPV Genotypes between $\leq 2009$ and $\geq 2010$ Timelines in Africa and Asia. Figure 4I, In Africa, the risk of HPV-52, 45, 58, 35, 39, 51, 16, 56, and 59 infections were 8\%, 14\%, 52\%, 56\%, $66 \%, 74 \%, 75 \%, 85 \%$, and approximately 2 times higher in $\leq 2009$ than in $\geq 2010$, respectively whereas in Asia, the risk of HPV-39, 51, 35, 56, 18, 66, 45, and 82 were $11 \%, 16 \%, 25 \%, 29 \%, 57 \%, 70 \%$, approximately 4 and 5 times in $\leq 2009$ than in $\geq 2010$, respectively. This suggests that in Africa the risk of HPV-6, 11, 18, 31, 33, 53, 66, 68, and 82 acquisition was higher in $\geq 2010$ than in $\leq 2009$, whereas the risk of HPV-6, 11, 16, 33, 52, 53, 58, 59, and 68 acquisition was higher in $\geq 2010$ than in $\leq 2009$.

and cervical cancer awareness, extent of high-risk sexual behaviour, prevalence of HPV infection and rate of HPV vaccination (Fitzmaurice et al., 2019; Arbyn et al., 2020; Klein et al., 2020). In Asia, although the rate of vaccination status is low $(15.0 \%)$, knowledge of risk factors for cervical cancer and willingness to get vaccinated among females aged 19-23 years are high; $98.8 \%$ and $92.5 \%$, respectively (Gollu and Gore, 2021). However, in Africa, HPV vaccine coverage in Africa (1.2-4.1\%), the knowledge of risk factors for cervical cancer $(7.8-11.8 \%)$ and willingness to get vaccinated $(26.0 \%-58.8 \%)$ among females aged 16-20 years are all low (Ndikom and Oboh,
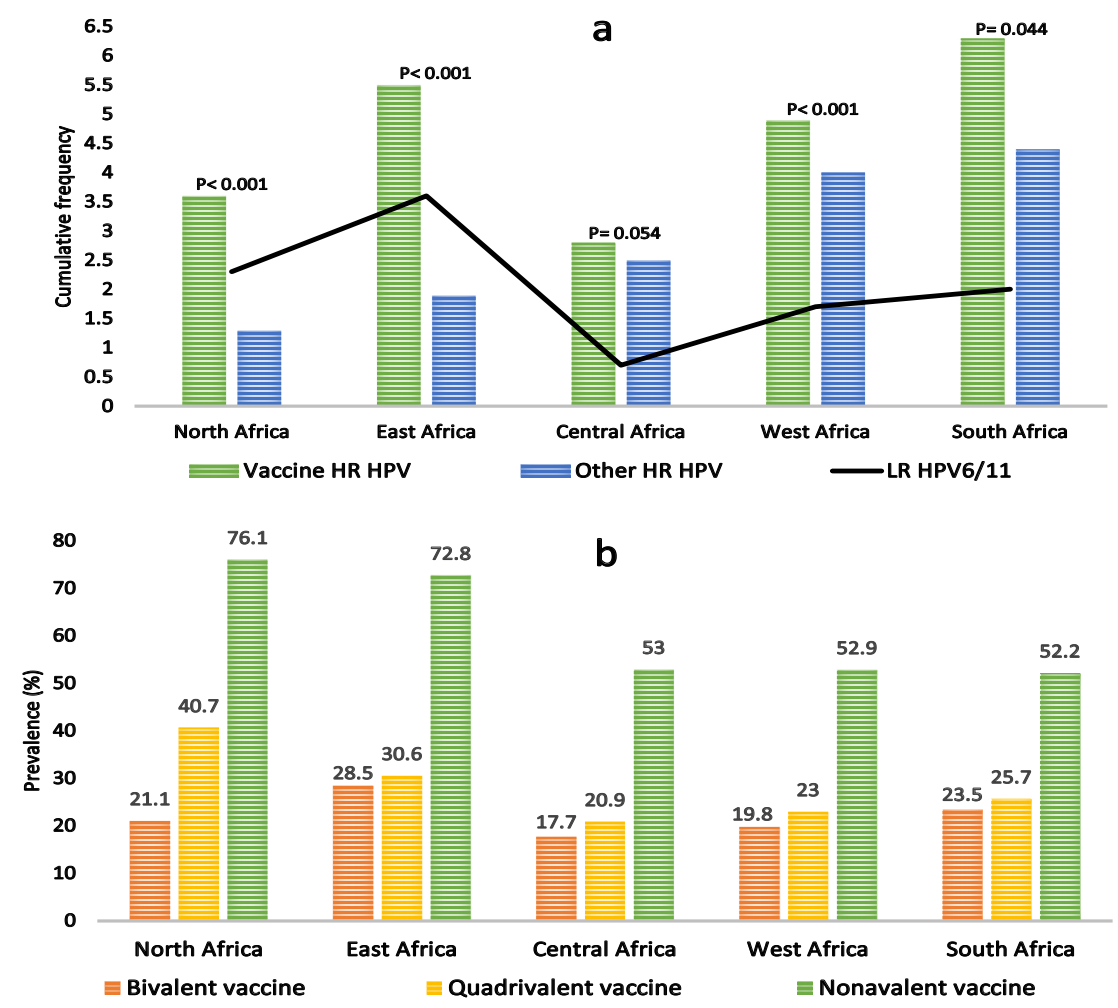

Figure 4II. HPV Genotypes and HPV Preventable by HPV Vaccines based on African Sub-regions (see supplementary data). Figure 4a shows that the prevalence of non-vaccine (other) hrHPV infection is highest in South Africa but lowest In North Africa. It also shows that the prevalence of vaccine hrHPV infection and lrHPV infection was higher in South Africa and East Africa, respectively while the prevalence of vaccine hrHPV and lrHPV infections were lower in central Africa. Higher differences in prevalence of vaccine and non-vaccine hrHPV types were observed in North and East African sub-regions $(\mathrm{p}<0.001)$. Figure $4 \mathrm{~b}$ shows that the prevalence of HPV infection preventable by quadrivalent and nonavalent vaccines were higher in North and East Africa than in other African sub-regions. 
2017; Kifle et al., 2020). The low HPV vaccine coverage in Africa has been associated with high cost of vaccine and skepticism of its safety (Sopian et al., 2019). Considering the lack of implementation of World Health Organization (WHO) and Center for Disease control and prevention (CDCP)'s recommendations (World Health Organisation, 2014; Center for Disease Control and Prevention, 2019), a high ASIR of cervical cancer is expected in Africa (Arbyn et al., 2020; Klein et al., 2020). However, there is a need to indirectly assess the past and ongoing cervical cancer related interventions. There is also the need to identify major contributors to the high ASIR and ASMR in Africa for appropriate channeling of future interventions following recommendations.

In the general population, this study revealed that HPV16, HPV52 and HPV58 were the most prevalent hrHPV types in Asia whereas HPV16, HPV18 and HPV52 were the most prevalent hrHPV infections in Africa. Considering the prevalence of hrHPV in abnormal cervix, this study revealed striking differences between Africa and Asia with regards to the prevalence of HPV35, HPV45, HPV31, HPV58, and HPV66. According to Hashim et al. (2020), the risk of developing CIN2+/CIN3+ among HPV16 and HPV18 positive women following a regular follow-up of 21 months are 24.4/19.9 and 16.2/10.8, respectively while the risk for women who are positive for other hrHPVs is $9.6 / 5.5$. Based on the latter, the substantial higher prevalence of HPV16 and HPV18 in Africa relative to Asia might also be an explanation for the difference in cervical cancer ASIR between the two continents as revealed by Fitzmaurice et al. (2019) and Arbyn et al. (2020). Considering the fact that HPV16 infection is associated with high mortality among HPV positive women (Zhao et al., 2017), it could be argued that the high prevalence of HPV is linked to the high ASMR or poor prognosis among African women (Chen et al., 2017; Fitzmaurice et al., 2019; Arbyn et al., 2020).

Namujju et al. (2011) stated that HPV16- and HPV18positive women have 11-22-fold and 45-58 increased risk of acquiring other hrHPVs, respectively. Thus, the higher prevalence of multiple HPV infection observed in Africa relative to Asia could be due to the higher prevalence of HPV16 and HPV18 in African women. The multiple HPV infection could be responsible for the higher ASIR in Africa than in Asia since higher prevalence of multiple infection has been reported in abnormal cervix than in normal cervix (Keita et al., 2009; Piras et al., 2011; Ndizeye et al., 2019). In addition, multiple HPV infection has been linked to increasing prevalence of human immunodeficiency virus (HIV) which in turn contributes significantly to cervical carcinogenesis (Klein et al., 2020). Thus, it could be suggested that the high ASIR of cervical cancer in Africa when compared with Asia stems from a cascade of event beginning from non-vaccine HPV infection and high multiple infection. In this study, South Africa had the highest prevalence of any HPV and multiple HPV infection while Central Africa had the least of both parameters. The difference between the African sub-regions in terms of ASIR of cervical cancer as revealed by Martel et al., (2017) could be due to high multiple HPV infections and HIV infection rate
(Hanischa et al., 2013; Taku et al., 2020).

According to Huh et al. (2017), nonavalent vaccine prevents $90 \%$ of cervical cancer worldwide. Their estimate is substantially higher than the estimate of this study $(69 \%)$. This could be attributed to their study not including any participants from African countries. Cervical cancers could be attributed to a single hrHPV type or multiple types such as HPV16, HPV18, HPV31, HPV33, HPV45, HPV52, and HPV58 which are preventable by available vaccines (de Martel et al., 2017). However, the vaccine hrHPV and non-vaccine hrHPV may not be effective in preventing multiple infection mediated cervical cancer involving HPV16/35, HPV16/53, HPV16/66, except in the event of cross-protection. Pirek et al. (2015) stated that there is an increased rate of malignant transformation in women with normal cervix and multiple HPV infection ( $<365$ days) than in women with normal cervix and single HPV infection, hence the need for continual screening, even among vaccinated women and immunocompromised women. Given the high rate of multiple infections in Africa, especially West and South Africa, nonavalent vaccine may offer better protection against cervical cancer than other vaccines. Additionally, the hrHPV type with the highest difference between African and Asian women diagnosed with cervical abnormalities was HPV35. Consequently, the high prevalence of HPV35 and its involvement in multiple infection may account for the higher ASIR in Africa than in Asia (Fitzmaurice et al., 2019; Arbyn et al. 2020). Sadly, none of the available vaccines offer protection against HPV35, the second most prevalent HPV types, which accounts for $12.4 \%$ of cervical abnormalities in Africa. Since HPV35 appears to be the major correlate of cervical carcinogenesis in Africa, continual Pap smear screening is recommended.

In this study, between 2004 and 2017, the prevalence of HPV infection and multiple infection decrease by $12.4 \%$ and $18.1 \%$ in Africa while they increased by $3.5 \%$ and $0.2 \%$ in Asia, respectively. The reason for the observed decrease in Africa could majorly be due to increasing awareness. On the other hand, considering the fact that the widely distributed vaccine in Africa are bivalent and quadrivalent vaccines (Muñoz et al., 2003; de Martel et al., 2017), the decrease could be attributed to HPV vaccination since the prevalence of HPV16 substantially decreased (5\%). Despite the fact that the overall prevalence of HPV infection decreased between 2004 and 2017 in Africa, the prevalence of HPV 33, 18, 6, 11, 82, 68, 31, 53 , and 66 increased by $0.2 \%, 0.3 \%, 0.4 \%, 0.5 \%, 0.5 \%$, $0.8 \%, 0.9 \%, 1.1 \%$, and $1.3 \%$, respectively within the same period, majority of the HPV types $(56 \% ; 5 / 9)$ are not covered by available vaccines. This may severely impact on the prevalence of cervical cancer in Africa. The reason however for the increased prevalence of HPV in Asia from 2004-2017 is still unknown. Interestingly, in Asia and Africa, the prevalence of HPV16 decreased by $16 \%$ and $5 \%$, respectively while the following HPV types increased by certain percentage in 2017: HPV31 (0.2\% vs $0.9 \%)$, HPV53 (0.2\% vs $1.1 \%)$, HPV33 (0.6\% vs $0.2 \%)$, HPV68 (0.8\% vs $0.7 \%)$, HPV 11 ( $1.3 \%$ vs $0.5 \%)$, and HPV6 (1.7\% vs $0.4 \%$, respectively). Differentially, the prevalence of HPV 52 and 58 increased in Asia by $0.5 \%$, 
and $1.5 \%$, respectively while in Africa the prevalence of HPV 18, 82 and 66 increased by $0.3 \%, 0.5 \%$ and $1.3 \%$, respectively (Table 4). Though the prevalence of HPV 6 , $11,31,33,53$, and 68 increased in both continents, the findings of this study suggest that if both continents adopt only nonavalent vaccines, it would still take a longer time to eradicate or significantly reduce cervical cancer in Africa than it would in Asia. This reiterates the fact that cervical cancer screening using Pap smear should still be an integral part of preventive measure in order to eliminate the disease in Africa by 2090 (Brisson et al., 2020).

The prevalence of vaccine and non-vaccine hrHPV were higher in South Africa than in other African subregion while the prevalence of vaccine and non-vaccine hrHPV were lowest in Central Africa and North Africa. This study suggests that majority, over $72 \%$, of cervical cancer attributable to HPV in North and East Africa could be prevented by vaccine, especially by using quadrivalent and nonavalent vaccines. Since 7 out of 12 countries are currently providing HPV vaccination at no cost for girls in East Africa, there is a higher chance of eliminating cervical cancer in the sub-continent by 2090 (Brisson et al., 2020; Njuguna et al., 2020). The findings of this study show that though nonavalent vaccine could prevent approximately $52 \%$ of cervical cancer attributable to HPV in Central, Western and Southern Africa, a tangible number of cervical cancer will still be observed in the sub-regions due to high prevalence of non-vaccine hrHPV.

\section{Limitation}

No grey literature was identified following our searches. This may constitute a limitation in this study.

In conclusion, This study revealed that the disparity between African and Asian women with regards to ASIR could be linked to high-risk HPV infection and multiple HPV types. It suggests that nonavalent vaccination could prevent over $90 \%$ of the cervical abnormalities in Africa.

\section{Author Contribution Statement}

This review was carried out and approved in collaboration between all the authors. JOO and AAN conceptualized and developed the study protocol. JOO, AAN, CFC, INO, SIO and ISO identified records for fulltext review and data extraction. JOO and AAN drafted the manuscript.

\section{Acknowledgements}

None.

\section{Ethical approval}

This study is not part of an approved student thesis. It is exempt from ethical review and approval, since the data that were reviewed and used for meta-analysis were retrieved and synthesized from studies published in indexed journals. Informed consents and ethical clearance were individually sought and obtained by authors of the included articles. Hence, ethical approval to conduct the study was not sought from any scientific bodies.

\section{Conflict of interest}

The authors declare that they have no financial or personal relationships which may have inappropriately influenced them in writing this article.

\section{References}

Akarolo-Anthony SN, Al-Mujtaba M, Famooto AO, et al (2013). HIV associated high-risk HPV infection among Nigerian women. BMC Infect Dis, 13, 1-6.

Al-Lawati Z, Khamis FA, Al-Hamdani A, et al (2020). Prevalence of human papilloma virus in Oman Genotype 82 and 68 are dominating. Int $J$ Infect Dis, 93, 22-7.

Arbyn M, Weiderpass E, Bruni L, et al (2020). Estimates of incidence and mortality of cervical cancer in 2018: a worldwide analysis. Lancet Global Health, 8, e191-203.

Awua AK, Severini A, Wiredu EK, et al (2020). SelfCollected Specimens Revealed a Higher Vaccine- and Non-Vaccine-Type Human Papillomavirus Prevalences in a Cross-Sectional Study in Akuse. Adv Prev Med. Doi: $10.1155 / 2020 / 8343169$

Bansal D, Elimi AA, Skariah S, et al (2014). Molecular epidemiology and genotype distribution of Human papillomavirus (HPV) among Arab women in the state of Qatar. J Trans Med, 12, 1-9

Belglaiaa E, Elannaz H, Mouaouya B, et al (2015). Human papillomavirus genotypes among women with or without HIV infection: an epidemiological study of Moroccan women from the Souss area. Infect Agents Cancer, 10, 1-10

Black E, Richmond R (2018). Prevention of Cervical Cancer in Sub-Saharan Africa: The Advantages and Challenges of HPV Vaccination. Vaccines, 6, 61

Boumba LMA, Qmichou Z, Mouallif M, et al (2015). Human Papillomavirus Genotypes Distribution by Cervical Cytologic Status among Women Attending the General Hospital of Loandjili, Pointe-Noire, Southwest Congo (Brazzaville). J Med Virol, 87, 1769-76.

Brisson M, Kim JJ, Canfell K, et al (2020). Impact of HPV vaccination and cervical screening on cervical cancer elimination: a comparative modelling analysis in 78 lowincome and lower-middle-income countries. Lancet, 395, 575-90.

Canfell K, Caruana M, Gebski V, et al (2017). Cervical screening with primary HPV testing or cytology in a population of women in which those aged 33 years or younger had previously been offered HPV vaccination: Results of the Compass pilot randomised trial. PLoS Med, 14, e1002388.

Center for Disease Control and Prevention (2019). Morbidity and Mortality Weekly Report. Human Papillomavirus Vaccination for Adults: Updated Recommendations of the Advisory Committee on immunization Practices. Weekly, 68, 698-700

Chen SL, Wang SC, Ho CJ, et al (2017). Prostate cancer mortality-to-incidence ratios are associated with cancer care disparities in 35 countries. Sci Rep, 7, 1-6.

de Martel C, Plummer M, Vignat J, Franceschi S (2017). Worldwide burden of cancer attributable to HPV by site, country and HPV type. Int J Cancer, 141, 664-70

Dols JA, Reid G, Brown JM, et al (2012). HPV type distribution and cervical cytology among HIV-positive Tanzanian and South African women. Obstet Gynecol.

Ezechi OC, Ostergren PO, Nwaokorie FO, et al (2014). The burden, distribution and risk factors for cervical oncogenic human papilloma virus infection in HIV positive Nigerian women. Virol J, 11, 5.

Fitzmaurice C, Abate D, Abbasi N, et al (2019). Global, regional, and national cancer incidence, mortality, years of life lost,

Asian Pacific Journal of Cancer Prevention, Vol 22 
years lived with disability, and disability-adjusted life-years for 29 cancer groups, 1990 to 2017: a systematic analysis for the global burden of disease study. JAMA Oncol, 5, 1749-68.

Ge Y, Zhong S, Ren M, et al. (2019). Prevalence of human papillomavirus infection of 65,613 women in East China. BMC Public Health, 19, 178

Ghedira R, Mahfoudh W, Hadhri S, et al (2016). Human papillomavirus genotypes and HPV16 variants distribution among Tunisian women with normal cytology and squamous intraepithelial lesions. Infect Agents Cancer, 11, 1-10.

Gollu AN and Gore CA (2021). Knowledge, Awareness and Attitude of Medical Students Regarding HPV Infection and HPV Vaccination. Asian Pac J Cancer Care, 6, 41-6

Guthrie BL, Rositch AF, Cooper JA, et al (2020). Human papillomavirus and abnormal cervical lesions among HIVinfected women in HIV-discordant couples from Kenya. Sexually transmitted infections.

Hanischa RA, Sowc PS, Tourec M, et al (2013). Influence of HIV-1 and/or HIV-2 infection and CD4 count on cervical HPV DNA detection in women from Senegal, West Africa. J Clin Virol, 58, 696-702.

Hashim D, Engesæter B, Skare GB, et al (2020). Real-world data on cervical cancer risk stratification by cytology and HPV genotype to inform the management of HPV-positive women in routine cervical screening. Br J Cancer, 122, 1715-23.

Huh WK, Joura EA, Giuliano AR, et al (2017). Final efficacy, immunogenicity, and safety analyses of a nine-valent human papillomavirus vaccine in women aged 16-26 years: a randomised, double-blind trial. Lancet, 2017.

Kantathavorn N, Mahidol C, Sritana N, et al (2015). Genotypic distribution human papillomavirus (HPV) and cervical cytology findings in 5906 Thai women undergoing cervical cancer screening programs. Infect Agent Cancer, 2015.

Keita N, Clifford GM, Koulibaly M, et al (2009). HPV infection in women with and without cervical cancer in Conakry, Guinea. Br J Cancer, 101, 202-8.

Kesheh MM, Keyvani H (2019). The prevalence of HPV genotypes in Iranian population: An Update. Iran J Pathol, 14, 197-205.

Kifle K, Kebede L, Taye J, et al (2020). Assessment of awareness and attitude on cervical cancer prevention among female preparatory students in Ziway town, Oromia Regional State, Ethiopia. Asian Pac J Cancer Care, 5, 265-71.

Klein C, Kahesa C, Mwaiselage J, et al (2020). How the cervical microbiota contributes to cervical cancer risk in sub-Saharan Africa. Front Cell Infect Microbiol, 10, 23.

Krings A, Dunyo P, Pesic A, et al (2019). Characterization of HumanPapillomavirus prevalence and risk factors to guide cervical cancer screening in the North Tongu District, Ghana. PLoS One, 14, e0218762.

Li Z, Liu F, Cheng S, et al (2016). Prevalence of HPV infection among 28,457 Chinese women in Yunnan Province, southwest China. Sci Rep, 6, 21039.

Liberati A, Altman DG, Tetzlaff J, et al (2009). The PRISMA statement for reporting systematic reviews and metaanalyses of studies that evaluate health care interventions: explanation and elaboration. PLoS Med, 62, e1-34.

Maranga IO, Hampson L, Oliver AW, et al (2013). HIV infection alters the dpectrum of HPV subtypes found in cervical smears and carcinomas from Kenyan women. Open Virol $J, 7,19-27$

Marembo T, Mandishora RD, Borok M (2019). Use of multiplex polymerase chain reaction for detection of high-risk human papillomavirus genotypes in women attending routine cervical cancer screening in Harare. Intervirol, 62, 90-5.

Mchome BL, Kjaer SK, Manongi R, et al (2020). HPV types, cervical high- grade lesions and risk factors for oncogenic human papillomavirus infection among 3416 Tanzanian women. Sex Transm Infect, 97, 56-62.

Menon SS, Rossi R, Harebottle R, et al (2016). Distribution of human papillomaviruses and bacterial vaginosis in HIV positive women with abnormal cytology in Mombasa, Kenya. Infect Agents Cancer, 11, 17.

Miyashita M, Agdamag DM, Sasagawa T, et al (2009). Highrisk HPV types in lesions of the uterine cervix of female commercial sex workers in the Philippines. J Med Virol, 81, 545-51.

Moher D, Liberati A, Tetzlaff J, Altman DG, Prisma Group (2009). Preferred reporting items for systematic reviews and meta-analyses: the PRISMA statement. PLoS Med, 6, e1000097.

Muderris T, Afsar I, Yıldız A, Varer CA (2019). HPV genotype distribution among women with normal and abnormal cervical cytology in Turkey. Rev Esp Quimioter, 32, 516-24.

Muñoz N, Bosch FX, de Sanjosé S, et al (2003). Epidemiologic classification of human papillomavirus types associated with cervical cancer. $N$ Engl J Med, 348, 518-27.

Mutombo AB, Benoy I, Tozin R, et al (2019). Prevalence and distribution of human papillomavirus genotypes among women in Kinshasa, The Democratic Republic of the Congo. $J$ Global Oncol, 5, 1-9.

Namujju PB, Waterboer T, Banura C, et al (2011). Risk of seropositivity to multiple oncogenic human papillomavirus types among human immunodeficiency virus-positive and -negative Ugandan women. J General Virol, 92, 2776-83.

Ndikom CM, Oboh PI (2017). Perception, acceptance and uptake of human papillomavirus vaccine among female adolescents in selected secondary schools in Ibadan, Nigeria. Afr $J$ Biomed Res, 20, 237- 44.

Ndizeye Z, Vanden Broeck D, Lebelo RL, et al (2019). Prevalence and genotype-specific distribution of human papillomavirus in Burundi according to HIV status and urban or rural residence and its implicationsfor control. PLoS One, 14, e0209303

Njuguna DW, Mahrouseh N, Onisoyonivosekume D, Varga O (2020). National policies to prevent and manage cervical cancer in East African Countries: A Policy Mapping Analysis. Cancers, 12, 1520.

Nyasenu YT, Gbeasor-Komlanvi FA, Issa SA, et al (2019). Prevalence of HPV among HIV-negative women of childbearing age in Lom'e, Togo. Future Virol, 14, 783-90

Obiri-Yeboah D, Akakpo PK, Mutocheluh M, et al (2017). Epidemiology of cervical human papillomavirus (HPV) infection and squamous intraepithelial lesions (SIL) among a cohort of HIV-infected and uninfected Ghanaian women. BMC Cancer, 17, 688.

Okolo C, Franceschi S, Adewole I, et al (2010). Human papillomavirus infection in women with and without cervical cancer in Ibadan, Nigeria. Infect Agents Cancer, 5, 24.

Park EK, Cho H, Lee SH, et al (2014). Human Papillomavirus Prevalence and Genotype Distribution among HIV-Infected Women in Korea. J Korean Med Sci, 29, 32-7.

Piras F, Piga M, Montis AD, et al (2011). Prevalence of Human Papillomavirus infection in women in Benin, West Africa. Virol J, 8, 514.

Pirek D, Petignat P, Vassilakos P, et al (2015). Human papillomavirus genotype distribution among Cameroonian women with invasive cervical cancer: a retrospective study. Sex Transm Infect, 91, 440-4.

Reddy D, Njala J, Stocker P, et al (2015). High-risk human papillomavirus in HIV-infected women undergoing cervical cancer screening in Lilongwe, Malawi: a pilot study. Int $J$ STD AIDS, 26, 379-87.

Said HM, Ahmed K, Burnett R, et al (2009). HPV genotypes in 
women with squamous intraepithelial lesions and normal cervixes participating in a community-based microbicide study in Pretoria, South Africa. J Clin Virol, 44, 318-21.

Sopian MM, Din SAT, Hussin H (2019). Obstacles to Implementing the HPV Vaccine: Is it Worth Pursuing or Not?. Asian Pac J Cancer Care, 4, 165-9.

Sweet K, Bosire C, Sanusi B, et al (2020). Prevalence, incidence, and distribution of human papillomavirus types in female sex workers in Kenya. Int J STD AIDS, 31, 109-18.

Taku O, Businge CB, Mdaka ML, et al (2020). Human papillomavirus prevalence and risk factors among HIVnegative and HIV-positive women residing in rural Eastern Cape, South Africa. Int J Infect Dis, 95, 176-82

Tan SC, Ismail MP, Duski DR, et al (2018). Prevalence and type distribution of human papillomavirus (HPV) in Malaysian women with and without cervical cancer: an updated estimate. Biosci Rep, 38, BSR20171268.

Thapa N, Maharjan M, Shrestha G, et al (2018). Prevalence and type-specific distribution of human papillomavirus infection among women in mid-western rural, Nepal- A populationbased study. BMC Infect Dis, 18, 338 .

Van S, Khac MN, Dimberg J, et al (2017). Prevalence of cervical infection and genotype distribution of human papilloma virus among females in Da Nang, Vietnam. Anticancer Res, 37, 1243-7.

Vassilakos P, Catarino R, Bougel S, et al (2016). Use of Swabs for dry collection of self-samples to detect human papillomavirus among Malagasy women. Infect Agents Cancer, 11, 13.

Vet JNI, de Boer MA, van den Akker BEWN, et al (2008). Prevalence of human papillomavirus in Indonesia: a population-based study in three regions. Br J Cancer, 99, 214-8.

Vidal AC, Murphy SK, Hernandez BY, et al (2011). Distribution of HPV genotypes in cervical intraepithelial lesions and cervical cancer in Tanzanian women. Infect Agents Cancer, 6, 20.

Wang R, Guo XL, Wisman GB, et al (2015). Nationwide prevalence of human papillomavirus infection and viral genotype distribution in 37 cities in China. BMC Infect Dis, 15, 257.

Wolday D, Derese M, Gebressellassie S, et al (2018). HPV genotype distribution among women with normal and abnormal cervical cytology presenting in a tertiary gynecology referral Clinic in Ethiopia. Infect Agents Cancer, 13, 28.

World Health Organisation (WHO) 2014. Comprehensive Cervical Cancer Control: A Guide to Essential Practice; World Health Organisation: Geneva, Switzerland; ISBN 978-92 4-154895-3.

Yakub MM, Fowotade A, Anaedobe CG, et al (2019). Human papillomavirus correlates of high grade cervical dysplasia among HIV-Infected women at a major treatment centre in Nigeria: a cross-sectional study. Pan Afr Med J, 33, 125.

Youssef MA, Abdelsalam L, Harfoush RA, et al (2016). Prevalence of human papilloma virus (HPV) and its genotypes in cervical specimens of Egyptian women by linear array HPV genotyping test. Infect Agents Cancer, 11,6 .

Zeng Z, Yang H, Li Z, et al (2016). Distribution of HPV Infection in China: Analysis of 51,345 HPV Genotyping Results from China's Largest CAP Certified Laboratory. $J$ Cancer, 7, 1037.

Zhang C, Huang C, Zheng X, Pan D (2018). Prevalence of human papillomavirus among Wenzhou women diagnosed with cervical intraepithelial neoplasia and cervical cancer. Infect Agents Cancer, 13, 37.
Zhang J, Zhang D, Yang Z, et al (2020). The role of human papillomavirus genotyping for detecting high-grade intraepithelial neoplasia or cancer in HPVpositive women with normal cytology: a study from a hospital in northeastern China. BMC Cancer, 20, 443.

Zhao J, Guo Z, Wang Q, et al (2017). Human papillomavirus genotypes associated with cervical precancerous lesions and cancer in the highest area of cervical cancer mortality, Longnan, China. Infect Agents Cancer, 12, 8.

Zhong TY, Zhou JC, Hu R, et al (2017). Prevalence of human papillomavirus infection among 71,435 women in Jiangxi Province China. J Infect Public Health, 10, 783-88.

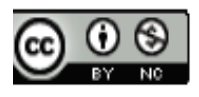

This work is licensed under a Creative Commons AttributionNon Commercial 4.0 International License. 